\title{
Building functional groups of marine benthic macroinvertebrates on the basis of general community assembly mechanisms
}

\author{
Alexandridis Nikolaos ${ }^{1,{ }^{*}}$, Bacher Cedric ${ }^{1}$, Desroy Nicolas ${ }^{2}$, Jean Fred ${ }^{3}$ \\ 1 IFREMER, Centre de Bretagne, DYNECO-LEBCO, CS 10070, 29280 Plouzané, France \\ 2 IFREMER, Laboratoire Environnement et Ressources de Bretagne Nord, 38 Rue du Port Blanc, BP \\ 70134, 35801 Dinard, France \\ ${ }^{3}$ Université de Brest, UBO, CNRS, IRD, Institut Universitaire Européen de la Mer, LEMAR, Rue Dumont \\ d'Urville, 29280 Plouzané, France \\ * Corresponding author : Nikolaos Alexandridis, email address : nikolaos.alexandridis@ifremer.fr
}

\begin{abstract}
:
The accurate reproduction of the spatial and temporal dynamics of marine benthic biodiversity requires the development of mechanistic models, based on the processes that shape macroinvertebrate communities. The modelled entities should, accordingly, be able to adequately represent the many functional roles that are performed by benthic organisms. With this goal in mind, we applied the emergent group hypothesis $(E G H)$, which assumes functional equivalence within and functional divergence between groups of species. The first step of the grouping involved the selection of 14 biological traits that describe the role of benthic macroinvertebrates in 7 important community assembly mechanisms. A matrix of trait values for the 240 species that occurred in the Rance estuary (Brittany, France) in 1995 formed the basis for a hierarchical classification that generated 20 functional groups, each with its own trait values. The functional groups were first evaluated based on their ability to represent observed patterns of biodiversity. The two main assumptions of the EGH were then tested, by assessing the preservation of niche attributes among the groups and the neutrality of functional differences within them. The generally positive results give us confidence in the ability of the grouping to recreate functional diversity in the Rance estuary. A first look at the emergent groups provides insights into the potential role of community assembly mechanisms in shaping biodiversity patterns. Our next steps include the derivation of general rules of interaction and their incorporation, along with the functional groups, into mechanistic models of benthic biodiversity.
\end{abstract}




\section{Highlights}

- The emergent group hypothesis is applied to benthic macroinvertebrate communities. 14 traits represent the role of benthic species in 7 community assembly mechanisms. The 240 species are classified into 20 emergent groups with their own trait values. Both niche and neutral constituents of the emergent group hypothesis are satisfied. We propose a systematic and testable method for quantifying functional redundancy.

Keywords: Assembly mechanisms, Benthic communities, Biological traits, Emergent groups, Functional diversity, Functional redundancy

\section{Introduction}

Biological communities (i.e. sets of co-occurring species) are at the heart of some of the most challenging issues currently raised in the field of ecology. These issues include the degree to which communities are shaped by stochastic versus deterministic processes, the potential for species traits to predict the structure and dynamics of communities and the role of environmental variability in space and time (Sutherland et al. 2013). The elucidation of the mechanisms of community assembly would not only enhance our fundamental understanding of ecological processes. It is also expected to increase our ability to conserve biodiversity and ecosystem function.

Function here refers to the second of the meanings assigned to the term by Jax (2005). It is associated with questions, such as "how is the whole sustained" or "what do specific parts contribute to this". Answering these questions is important, because we value the services provided by a functioning whole. Yet, in view of the current rate 
of environmental change and its potential impacts on biodiversity (Bellard et al. 2012), we cannot reliably answer them without first addressing the questions that Jax (2005) linked to the functioning of the specific parts, such as "which processes occur" or "how do organisms interact with each other and with their environment".

The effort to answer these questions in the marine benthos has been dominated by statistical methods of multivariate analysis (Clarke 1993; Legendre \& Gauthier 2014). These methods rely on data from temporal and/or spatial sampling schemes, aimed at capturing the species abundance patterns of a system's macro-, meio- or microbenthic compartment. They often use correlations between environmental variables and community composition with the goal of explaining variations in the latter (ter Braak \& Prentice 2004). With the addition of tools for the analysis of spatial and temporal patterns (Dray et al. 2006; Blanchet et al. 2008) multivariate analysis has become a very efficient exploratory technique. However, its correlative nature, along with its difficulty to account for key ecological phenomena, has restricted its ability to reveal the role of community shaping processes (James \& McCulloch 1990).

In response to the limitations of statistical modelling, efforts have been made to adopt a more mechanistic approach, mostly in the form of dynamic food web models (Yodzis \& Innes 1992) and static trophic network analyses (Ulanowicz 2004). The amounts of data and knowledge that are typically required by such approaches, along with issues of model complexity and tractability, have set a limit to the number of modelled entities. In spite of efforts to address these issues through the application of tools, such as Ecopath with Ecosim (Ortiz \& Wolff 2002) or the inverse method (Garcia et al. 2011), mechanistic models tend to lack the level of detail that is needed to account for the functioning of benthic communities. The host of biotic interactions that are responsible for shaping these systems is hardly limited to what can be 
represented by a food web (Menge 1995). In spite of recent attempts to integrate non-trophic interactions into food web models (Kéfi et al. 2012), the majority of community assembly mechanisms are seldom included in models of marine benthos.

Trait-based approaches have been suggested as an alternative to food web models (Ings et al. 2009). Biological traits have been increasingly employed in the analysis of the functional composition of benthic communities (Bremner 2008). The emergence of the concept of functional diversity has raised questions, such as "what types of traits", "which traits" or "how many traits" should be considered. Petchey et al. (2006) argue that the answers depend on the scope of each study, emphasizing the potential for functional classifications of organisms to be nested and the need to treat each classification as a testable hypothesis. Bremner et al. (2006b) suggest including as many traits as possible in biological traits analyses, with recent studies following suit (e.g. Darr et al. 2014; Jimenez et al. 2016). Trait-based modelling approaches have, on the other hand, focused on the most studied processes in the marine benthos: feeding behaviour and substrate modification (Pearson 2001). The representation of these mechanisms offers valuable information on the contribution of existing communities to the functioning of the system, but it provides very little insight into future trajectories following natural or anthropogenic environmental change.

A variety of ecological theories pertaining to environmental filtering, trophic interactions, resource partitioning, life history trade-offs and response to disturbance have been successfully employed to explain observations of benthic communities. They could be used to generate reliable predictions of benthic biodiversity, if they took the form of mathematical formulations linking a system's primary functional components. The latter should be generated through a systematic and testable procedure and possess a clear role in various community assembly mechanisms. 
The framework developed by Boulangeat et al. (2012) for communities of terrestrial vegetation is particularly well-suited for this purpose. It employs the emergent group hypothesis $(E G H)$, which assumes functional equivalence within (neutrality) and functional divergence between (niche differentiation) groups of species (Hérault 2007). Its application is based on a matrix of species traits that represent their role in important community assembly mechanisms. Group emergence results from correlations among the traits, which are indicative of adaptive responses and evolutionary constraints (Lavorel et al. 1997).

The aggregation of ecosystems through the construction of functional groups is based on the concept of functional redundancy, which is central to theories relating biodiversity variations to ecosystem function (Rosenfeld 2002). Although the exact nature of this relationship has been subject to debate (Grime 1997), its existence is beyond dispute (Srivastava \& Vellend 2005). This is why the level of functional redundancy with regard to the assembly of communities, the engines of biodiversity, is particularly important for the conservation of ecosystem function. This level can be demonstrated as the acceptable level of ecological aggregation, i.e. the minimum number of groups that can adequately represent community function. It appears to vary in predictable ways (Hairston \& Hairston 1993), but its accurate assessment requires a good understanding of assembly mechanisms (Walker 1992).

In spite of recent advances in the quantification of functional redundancy (Muntadas et al. 2016; van der Linden et al. 2016), its assessment remains highly prone to subjectivity, especially with regard to the number of biological traits (Jax 2005). The framework of Boulangeat et al. (2012) addresses this issue, by defining a specific number of important community assembly mechanisms that need to be explicitly represented. Trait categorization is generally lacking among functional 
studies of benthic communities. Even when traits are explicitly assigned to a set of general functions (e.g. Törnroos \& Bonsdorff 2012), this is done in order to rather interpret the results of the study than guide the process of biological traits selection. The framework also allows the nesting of finer functional differences within broader ones. This is achieved through the separation of organisms into broad groups with a common resource base, whose consumption is further differentiated based on finer group dissimilarities. Finally, putting the emergent grouping to the test is central to the framework and allows defining the acceptable level of ecological aggregation as the minimum number of groups for which the assumptions of the EGH are supported by observations. Boulangeat et al. (2012) tested the niche constituent of the EGH, by comparing its assumptions with what could be observed in their system. Here, we take their approach one step forward, by investigating the second constituent of the $\mathrm{EGH}$, concerning the neutral behaviour of species within each functional group.

In this study, we revisit a benthic macroinvertebrates abundance data set from the Rance estuary (Brittany, France), previously explored with the use of traditional multivariate analyses (Desroy 1998). We combine it with a matrix of biological traits, with the goal of aggregating the system through the construction of functional groups. We investigate both niche and neutral attributes of the emergent grouping, gaining insights into the components of functional diversity and redundancy in benthic communities. In doing so, we integrate statistical tools and ecological mechanisms into a quantitative approach toward defining the acceptable level of ecological aggregation. The present study is a first step toward the development of models of benthic community assembly mechanisms, with the generated functional groups as their entities. The application of this generic modelling approach to the Rance estuary is expected to describe the stability characteristics of macroinvertebrate communities 
as well as their responses to well-documented perturbations, such as the occurrence of particularly cold winters or the introduction of invasive species (Desroy 1998).

Methods

\section{1}

Study site

The framework for the construction of functional groups was applied to the Rance estuary (Brittany, France), in the southern part of the English Channel (Fig. 1). The site is characterized by the presence of a tidal power plant at its mouth, comprising a lock, the generating station proper, a rock dike and a $115 \mathrm{~m}$ wide removable dam made up of 6 sluice gates. The system was fundamentally altered during the construction of the plant (1963-1966), after which it was allowed to gradually return to a more natural state (Kirby \& Retière 2009).

The operating constraints of the installation impose highly specific "tidal" conditions on the estuary: (1) mean water level is elevated by approximately $2.5 \mathrm{~m}$, (2) slack water periods are particularly long (up to $5 \mathrm{~h}$ ), (3) emersion time may be half that of the open sea and (4) the tidal range varies between $4.0 \mathrm{~m}$ and $5.5 \mathrm{~m}$ compared to $9.5 \mathrm{~m}$ (mean value) in the open sea, depending on which direction the turbines are operating (Retière 1994). Reduction in tidal range is correlated with a reduction in the surface area of the intertidal zone; the exposed zone accounts today for $50 \%$ of the total surface of the Rance estuary, compared to $70 \%$ before the construction of the plant. Maximum water depth is $17 \mathrm{~m}$ at low tide, but the main part of the basin is $5-6 \mathrm{~m}$ deep. Two areas of differing salinities can be identified: the marine reservoir, in which deep-water salinity remains higher than 30 , and the 
upstream estuary of brackish water (Retière 1994). The junction between brackish and marine waters has moved about $5 \mathrm{~km}$ upstream since the scheme was built.

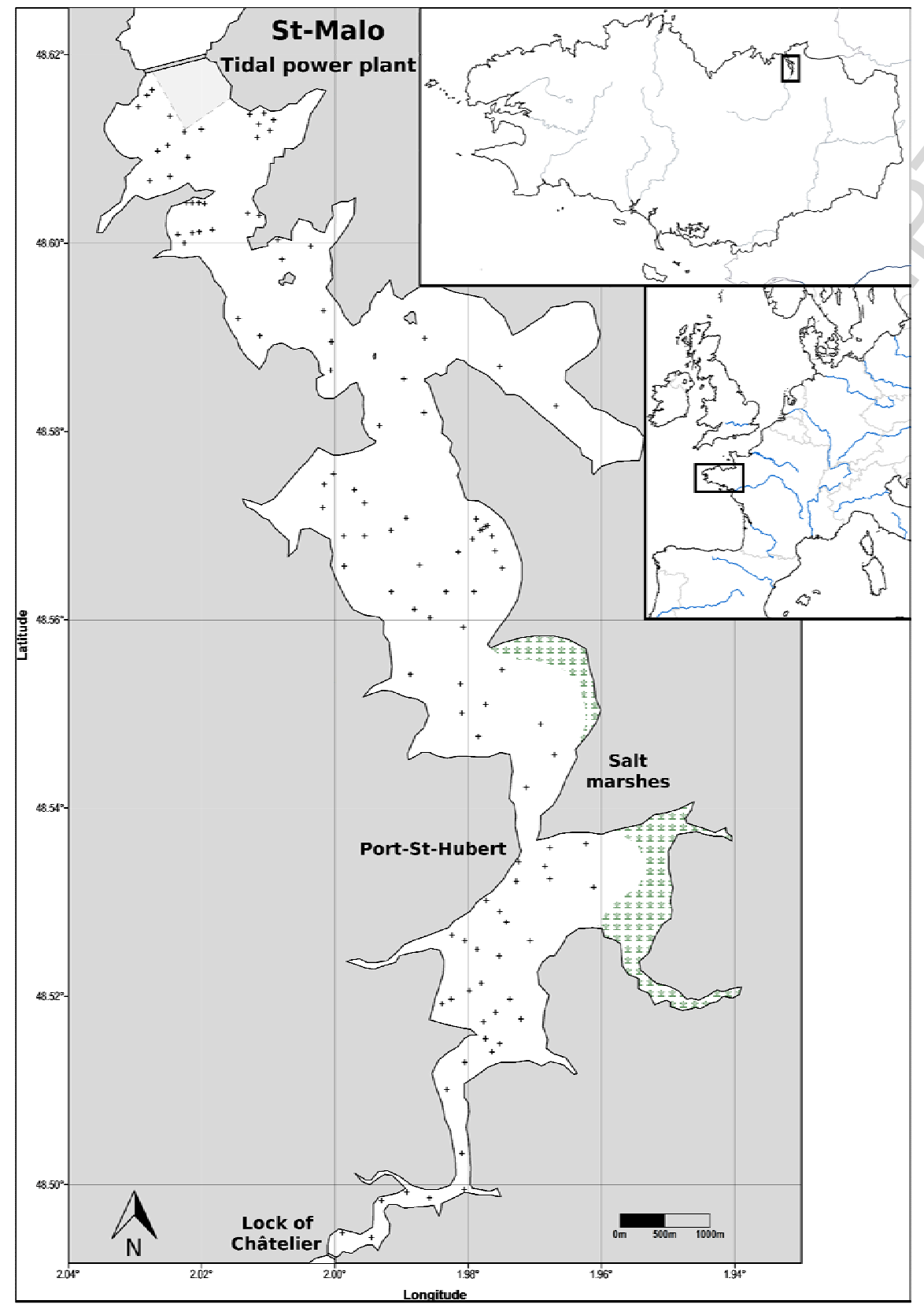

Fig. 1. Map of the study site. The Rance estuary is situated on the northern coast of Brittany, France. Crosses indicate the location of the 113 stations that were sampled in the spring of 1995 . The tidal power plant is located at the mouth of the estuary, south of the city of St-Malo 
The strong sluice and turbine currents have eroded parts of the riverbed. Sandbanks closest to the dam have shifted and the bed is more or less covered with gravel or pebbles (Retière 1994). Meanwhile, long periods of slack water have promoted the deposition of fine particles in coves and bays (Bonnot-Courtois \& Lafond 1991). From downstream to upstream of the estuary, pebbles and coarse sands are replaced by medium and fine sands, muddy sands and finally muds, beyond Port-St-Hubert. A similar sequence is observable from the central channel to the banks. Natural silting is presumed to have increased since operation of the tidal power plant started. In the upstream part of the estuary, sedimentation rate increased from $0.5 \mathrm{~cm} \mathrm{y}^{-1}$ before the scheme to $2.7 \mathrm{~cm} \mathrm{y}^{-1}$ after (Bonnot-Courtois, Ecole Pratique des Hautes Etudes, Dinard, France, personal communication).

\section{2}

Sampling methods

A grid of 113 stations was sampled in April 1995, prior to the spring recruitment (Fig. 1). Two replicate samples were collected at each of 103 submerged stations using a $0.1 \mathrm{~m}^{2}$ Smith Mac-Intyre grab, while 10 emerged stations were sampled using a hand corer (5 replicates; replicate area of $1 / 55 \mathrm{~m}^{2}$ ) to a depth of $20 \mathrm{~cm}$. The number of replicates is assumed to be sufficient to characterize the assemblage of species that can be found at each station. Although densities of organisms were extrapolated to a standard surface area, some bias was unavoidably introduced, due to the different characteristics of the sampling gears. All samples were gently washed in situ through a $1 \mathrm{~mm}$ sieve and preserved in $4.5 \%$ formalin before being sorted, identified and counted in the laboratory. Macroinvertebrates retained on the mesh 
were determined at species level when possible. A total of 240 species or higher taxonomic groups belonging to 9 phyla were thus identified.

\section{3}

Design and application

Our approach draws on the work of Boulangeat et al. (2012), who employed the $\mathrm{EGH}$ for the classification of terrestrial plant species into groups with similar ecological strategies. Much like their approach, our own is divided into five steps (Fig. 2), with the respective ecological assumptions and methodological framework presented below.

\subsection{1}

Step 1: selecting biological traits

The objective of this step was to select species characteristics that describe the role of the average individual of each species in the most important community assembly mechanisms. The list of mechanisms was mostly adopted from the framework of Boulangeat et al. (2012), with a few adjustments, in order to adapt it to the special attributes of estuarine benthic systems. The choice of the traits was made based on both the nature of the community assembly mechanisms and the quality of the data that could be found for each of the traits.

Since community assembly mechanisms include competition for a limited amount of resources, we first identified food and space as the basic resources for which benthic organisms compete. Space was assumed to be two-dimensional, while food was defined with the goal of dividing species into groups with a common resource base. The wide-spread adoption of facultative feeding modes only allowed 
for a distinction between species that feed on algae and detritus on the one hand and those characterized as predators and scavengers on the other.

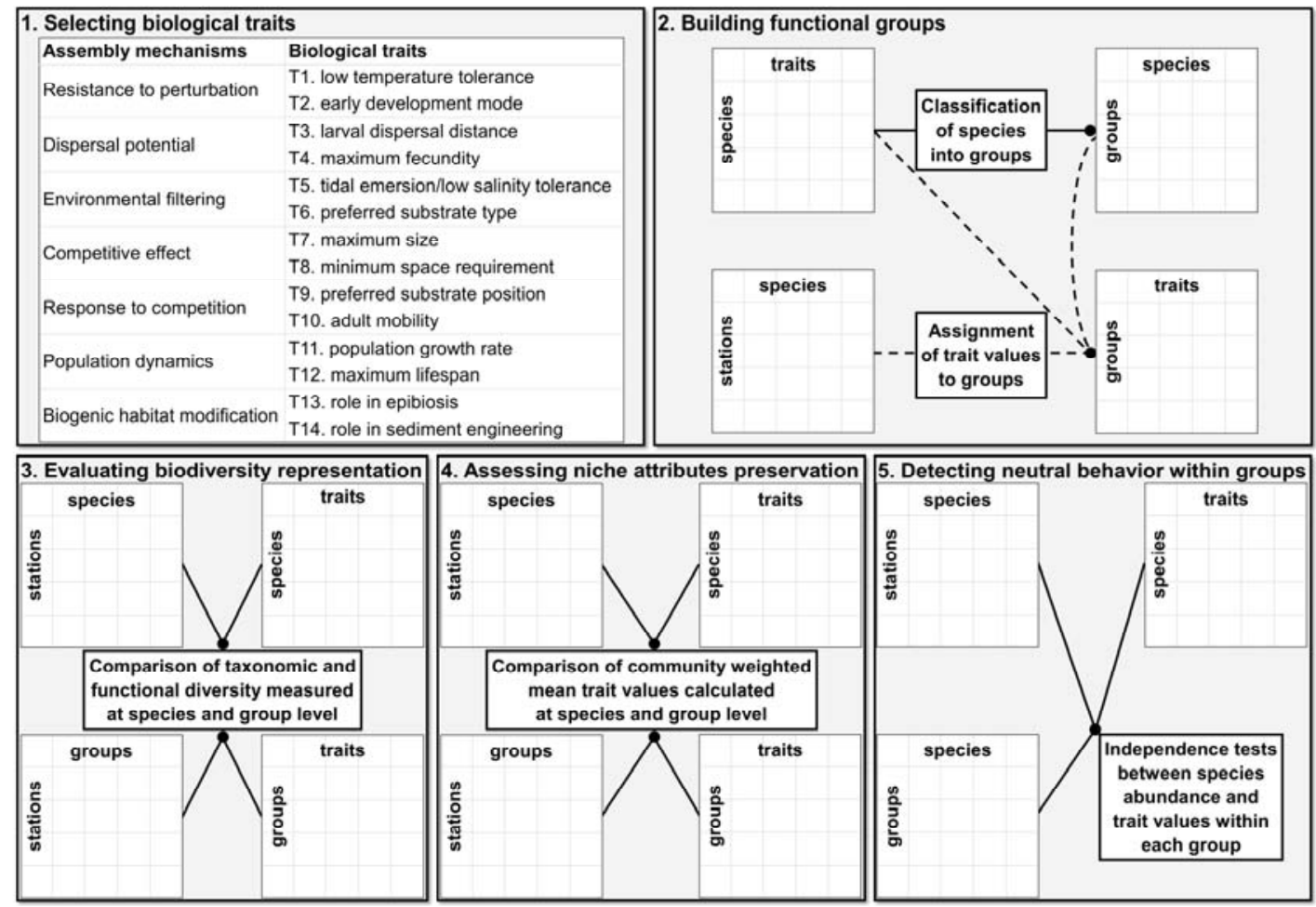

Fig. 2. Schematic representation of the 5 steps that comprise the methodology of functional grouping. In step 1, 14 biological traits were selected, representing 7 community assembly mechanisms. For details, see Table 1 . In step 2, a matrix of species trait values formed the basis for the classification of species into functional groups (solid line). The two matrices, combined with data of species abundance, allowed the assignment of trait values to the functional groups (dashed lines). In step 3, taxonomic diversity and functional divergence were measured for each station at the level of species and functional groups. Measures at the two levels were then compared, in order to evaluate the representation of biodiversity by the functional groups. In step 4, community weighted mean trait values were calculated for each 
station at the level of species and functional groups. Calculations at the two levels were then compared, in order to assess the preservation of niche attributes by the functional groups. In step 5, the independence between species abundance at each station and their trait values was tested within each functional group and the rejection proportion for every trait was used as an indication of departures from neutrality

The rest of the biological traits represent seven community assembly mechanisms. The initial goal was for each mechanism to be represented by two traits, so that one set of traits could be used for the species classification and the other for the cross-validation of the resulting grouping. The lack of redundancy in the content of the two sets of traits obliged us to abandon this goal and use all fourteen traits for the classification of the species into groups. The seven community assembly mechanisms are: (1) resistance to perturbation, (2) dispersal potential, (3) environmental filtering, (4) competitive effect, (5) response to competition, (6) population dynamics and (7) biogenic habitat modification. Details about the selected biological traits and the assignment of trait values to species can be found in Table 1 .

The vast majority of the information that was required for the assignment of trait values to the species of the system was provided by the following online databases: eol.org, genustraithandbook.org.uk, marinespecies.org, marlin.ac.uk and speciesidentification.org. The remainder was acquired from expert knowledge. Very often the lack of appropriate information for a particular species obliged us to look for data at higher taxonomic levels. The quality of the available information for the ensemble of species and biological traits dictated the resolution of the values that were assigned to them (see Table S1 in the Supplementary Material). 
Table 1. List of community assembly mechanisms, biological traits that represent the species' role in them, trait values and comments about their assignment to species

\begin{tabular}{|c|c|c|c|}
\hline Mechanisms & Biological traits & Trait values & Comments \\
\hline \multirow{2}{*}{$\begin{array}{l}\text { Resistance to } \\
\text { perturbation }\end{array}$} & $\begin{array}{l}\text { T1. low temperature } \\
\text { tolerance }\end{array}$ & eurythermal / stenothermal & $\begin{array}{l}\text { Species that can tolerate continued exposure to single-digit } \\
\text { temperatures (eurythermal) were distinguished from those } \\
\text { that cannot (stenothermal). }\end{array}$ \\
\hline & $\begin{array}{l}\text { T2. early development } \\
\text { mode }\end{array}$ & planktonic / laid / brooded & $\begin{array}{l}\text { Trait values should define a gradient of increasing ability to } \\
\text { cope with perturbations during the early life stages, due to } \\
\text { increasing investment in early offspring survival. }\end{array}$ \\
\hline \multirow{2}{*}{$\begin{array}{l}\text { Dispersal } \\
\text { potential }\end{array}$} & $\begin{array}{l}\text { T3. larval dispersal } \\
\text { distance }\end{array}$ & short / long & $\begin{array}{l}\text { Species were separated in two groups based on their } \\
\text { maximum observed dispersal distance, with a distance of } \\
10 \mathrm{~km} \text { used as the breaking point. }\end{array}$ \\
\hline & $\begin{array}{l}\text { T4. maximum } \\
\text { fecundity }\end{array}$ & low / high & $\begin{array}{l}\text { Species were separated in two groups, with the number of } \\
1000 \text { eggs produced by a female of each species per year } \\
\text { used as the breaking point. }\end{array}$ \\
\hline \multirow{2}{*}{$\begin{array}{l}\text { Environmental } \\
\text { filtering }\end{array}$} & $\begin{array}{l}\text { T5. tidal emersion / } \\
\text { low salinity tolerance }\end{array}$ & $\begin{array}{l}\text { emersed / euryhaline / } \\
\text { stenohaline }\end{array}$ & $\begin{array}{l}\text { Soft bottom species that can tolerate long tidal exposure } \\
\text { should be able to tolerate low salinity (emersed). Immersed } \\
\text { species either can tolerate salinities that differ greatly from } \\
\text { those of the open sea (euryhaline) or cannot (stenohaline). }\end{array}$ \\
\hline & $\begin{array}{l}\text { T6. preferred } \\
\text { substrate type }\end{array}$ & $\begin{array}{l}\text { mud / muddy sand / sand / } \\
\text { muddy gravel / gravel / rock }\end{array}$ & $\begin{array}{l}\text { The assignment of one value to each species represented } \\
\text { its greatest substrate affinity, but was often too restrictive. }\end{array}$ \\
\hline \multirow{2}{*}{$\begin{array}{l}\text { Competitive } \\
\text { effect }\end{array}$} & T7. maximum size & $\begin{array}{l}1 \mathrm{~cm} / 2 \mathrm{~cm} / 10 \mathrm{~cm} / 20 \mathrm{~cm} / \\
40 \mathrm{~cm}\end{array}$ & $\begin{array}{l}\text { Trait values should define a gradient of increasing area that } \\
\text { can be searched for food or distance from the substrate, } \\
\text { which enhances food availability (McLean \& Lasker 2013). }\end{array}$ \\
\hline & $\begin{array}{l}\text { T8. minimum space } \\
\text { requirement }\end{array}$ & $\begin{array}{l}0.003 \text { / } 0.1 \text { / } 49.5 \\
\text { (min. / median / max.) } \\
\text { Values do not represent } \\
\text { absolute, but relative levels. }\end{array}$ & $\begin{array}{l}\text { Species with the lowest trait value should compete best for } \\
\text { space (Tilman 1980). Trait values were derived from data on } \\
\text { body mass (Robinson et al. 2010) and use of an exponent } \\
\text { of } 3 / 4 \text { from the metabolic theory of ecology (Jetz et al. 2004). }\end{array}$ \\
\hline \multirow{2}{*}{$\begin{array}{l}\text { Response to } \\
\text { competition }\end{array}$} & $\begin{array}{l}\text { T9. preferred } \\
\text { substrate position }\end{array}$ & terface / epifauna & $\begin{array}{l}\text { Living deep in the sediment (infauna), at its upper layer } \\
\text { (interface) or on its surface (epifauna) should allow species } \\
\text { co-existence in spite of established competitive hierarchies. }\end{array}$ \\
\hline & T10. adult mobility & mobile / sessile & $\begin{array}{l}\text { Differences in the ability of species to move should lead to } \\
\text { resource partitioning and avoidance of competition. }\end{array}$ \\
\hline \multirow{2}{*}{$\begin{array}{l}\text { Population } \\
\text { dynamics }\end{array}$} & $\begin{array}{l}\text { T11. population } \\
\text { growth rate }\end{array}$ & $\begin{array}{l}0.27 \text { / } 2.14 \text { / } 6.95 \\
\text { (min. / median / max.) } \\
\text { Values do not represent } \\
\text { absolute, but relative levels. }\end{array}$ & $\begin{array}{l}\text { Trait values were derived from data on body mass } \\
\text { (Robinson et al. 2010) and use of an exponent of }-1 / 4 \text { from } \\
\text { the metabolic theory of ecology (Savage et al. 2004). }\end{array}$ \\
\hline & $\begin{array}{l}\text { T12. maximum } \\
\text { lifespan }\end{array}$ & $1 \mathrm{yr} / 2 \mathrm{yr} / 10 \mathrm{yr} / 20 \mathrm{yr}$ & $\begin{array}{l}\text { Different trait values should reflect differentiations in species } \\
\text { population dynamics. }\end{array}$ \\
\hline \multirow{2}{*}{$\begin{array}{l}\text { Biogenic } \\
\text { habitat } \\
\text { modification }\end{array}$} & T13. role in epibiosis & basibiont / epibiont / neutral & $\begin{array}{l}\text { Species that can grow on other organisms (epibiont) were } \\
\text { distinguished from those that also provide biotic substrate } \\
\text { (basibiont). Neutral species do not participate in epibiosis. }\end{array}$ \\
\hline & $\begin{array}{l}\text { T14. role in sediment } \\
\text { engineering }\end{array}$ & $\begin{array}{l}\text { stabilizer / destabilizer / } \\
\text { neutral }\end{array}$ & $\begin{array}{l}\text { Sediment destabilizing species should inhibit sessile, tube } \\
\text { building species (stabilizers) and vice versa (Posey 1987). } \\
\text { Neutral species do not participate in sediment engineering. }\end{array}$ \\
\hline
\end{tabular}




\subsection{2}

Step 2: building functional groups

This step aims at reducing a community of benthic macroinvertebrates to its principal functional components, by identifying emergent groups of species (Hérault 2007). It was applied separately for consumers of algae/detritus and predators/scavengers, because the concept of functional equivalence, which is central to the $\mathrm{EGH}$, is defined for trophically similar sympatric species (Hubbell 2005). The first task involved calculating a distance matrix for both groups of species, based on the rest of the biological traits. Since our list included continuous, ordinal, nominal and binary traits, we opted for the Gower distance (Gower 1971). These matrices formed the basis for the application of an agglomerative hierarchical clustering technique, the unweighted pair group method with arithmetic mean (Sokal \& Michener 1958). The two generated dendrograms were consecutively pruned at 0.4 and 0.3 distance levels, without, for practical reasons, allowing the formation of groups with only one species.

In order to be able to treat the newly formed groups as independent functional components, we needed to attribute trait values to them. We did that by employing the mass ratio hypothesis (Grime 1998), which predicts that the functional identity of a group of species is determined by the trait values of the dominant abundance contributors. We measured the abundance contribution of each species in its group, by calculating its median abundance at the stations where it was present. For the ordinal, nominal and binary traits, a group's trait value was defined as the dominant value, as far as the abundance contribution of its species was concerned. For the continuous traits, a group's trait value was defined as the mean trait value of all the 
species in the group, weighted by their abundance contribution. Each group was, finally, assigned a representative species, which was the one with the highest abundance contribution in the group. In case of ties or close calls, the species with the highest body mass was chosen to represent the group.

\subsection{3}

Step 3: evaluating biodiversity representation

Once functional groups were built, we had to assess their efficiency at representing natural biodiversity patterns. This need stems from the loss of information that is inherent to the process of classifying a number of species into a much smaller number of groups. We in fact wanted to know if this loss of information lay within acceptable limits, or if, instead, it severely impaired the ecological pertinence of the imposed grouping. If we assume that information at the species level provides an adequate representation of biodiversity, we could reach our goal by comparing biodiversity measurements at this level with the same measurements made at the level of functional groups. Since the role of the groups as functional components of the system was what we were especially interested in, we did not want to be limited to measures of taxonomic diversity, but we wanted to include measures of functional diversity as well.

One framework that offers this possibility is Rao's quadratic entropy, $Q$ (BottaDukát 2005). For an assemblage of $T$ taxa characterized by the relative abundance vector $\mathbf{p}=\left(p_{1}, p_{2}, \ldots, p_{T}\right)$, it is defined as

$$
Q=\sum_{i=1}^{T-1} \sum_{j=i+1}^{T} d_{i j} p_{i} p_{j}
$$


where $d_{i j}$ is the functional distance between the $i$-th and $j$-th taxa $\left(d_{i j}=d_{j i}\right.$ and $\left.d_{i i}=0\right)$. Assuming functional equidistance among taxa $\left(d_{i j}=1\right)$, it equals the complement of the Simpson dominance index, thus expressing the probability that two individuals taken at random from an assemblage belong to different taxa. When combined with a functional distance matrix for the taxa in question, like the one previously calculated with the help of the Gower distance, the same index becomes a measure of functional divergence. In this case, Rao's quadratic entropy expresses the average functional distance between two randomly selected individuals of an assemblage. We calculated both versions of the index for all 113 assemblages. If the species-level measures of diversity showed a high correlation with the same measures calculated at the level of functional groups, we could say that the transition from the former level to the latter entailed an acceptable amount of information loss.

\subsection{4}

Step 4: assessing niche attributes preservation

Niche theory predicts that the dynamics of species populations are controlled by their characteristics (Hutchinson 1957). Species with divergent trait values exhibit differential responses to dissimilar environments, thus generating the observed distribution patterns of not only the species, but the respective traits as well. The $\mathrm{EGH}$, through its niche constituent, assumes that the same holds true for the emergent groups of species (Hérault 2007). The interaction of the environment with the organisms through the relevant biological traits should now take place at the level of functional groups, but the resulting trait distribution should not deviate from the one observed at the species level. One way to assess the validity of this assumption is by 
comparing the functional identity of dominant taxa in an assemblage measured at the species level, with the same metric measured at the level of functional groups.

An indicator of the functional identity of dominant taxa in an assemblage is the community weighted mean (Garnier et al. 2004), which represents the expected trait value for a random community sample. For the ordinal, nominal and binary traits, the community weighted mean was defined as the dominant trait value, as far as taxa abundance is concerned. For the continuous traits, the same measure was defined as the mean trait value of all the taxa in an assemblage, weighted by their relative abundance. The comparison of community weighted means calculated at species and group level for the ordinal, nominal and binary traits was made by deriving the proportion of the assemblages for which the two calculations agreed. For the continuous traits, we examined the correlation between the values calculated at the levels of species and functional groups. High proportions of agreement or correlation coefficients would indicate that the representation of the system at the level of functional groups preserved the niche characteristics of the original one.

\subsection{5}

Step 5: detecting neutral behaviour within groups

The second major assumption of the $\mathrm{EGH}$ is that the organisms that belong to the same functional group are ecologically equivalent (Hérault 2007). This means that any differences in trait values that the organisms of a group might exhibit, should be random and, therefore, not associated with differences in their abundance (Hubbell 2005). If this is not the case, the dynamics within the groups could not be considered as neutral, but rather controlled by the values of the trait. Since we only had information on inter-specific trait variation, we could examine this assumption, by 
checking for high levels of covariation between the abundance of a group's species in an assemblage and the respective trait values.

For the ordinal, nominal and binary traits, this could be done by performing the Kruskal-Wallis independence test (Kruskal \& Wallis 1952), while for the continuous traits, we opted for Hoeffding's test (Hoeffding 1948). They both test for independence between the abundance of a group's species in an assemblage and the respective trait values and were repeated for each of the functional groups and assemblages. The proportion of rejection of these tests over all groups and assemblages was calculated for each of the traits and was considered as a measure of departure from neutrality for the within-group dynamics, with regard to the respective trait. A high value for a trait would indicate that high covariation between species abundance and trait values occurred more often than expected by chance and would thus challenge the assumption of ecological equivalence among the species of a group, as far as this particular trait is concerned.

All analyses were performed using the statistical software $R$ version $3.2 .2(R$ Core Team 2015) with the packages cluster (Maechler et al. 2013), FD (Laliberté et al. 2014), ade4 (Dray \& Dufour 2007) and Hmisc (Harrell \& Dupont 2015).

Results

\section{1}

Building functional groups

The dendrograms displaying functional distance among the species of the two feeding groups were pruned at 0.4 and 0.3 distance levels, thus allowing the 
emergence of 7 intermediate and 20 final groups, respectively. Unlike the transition from 7 to 20 functional groups, further classification into 30 groups did not result in improved agreement of observations with theoretical assumptions and it was, therefore, dismissed. The abundance contribution and the trait values of all 20 groups' constituent species determined the representative species and the values which were assigned to the functional groups for each of the 14 biological traits (Table 2). The trait values of the representative species may not always correspond to those of the functional groups, since all of a group's species contributed to the definition of the latter. The representative species for now only serve to communicate the results of the grouping to experts with knowledge of the system and its species.

The emergent functional groups demonstrate a variety of combinations with regard to their assigned trait values, with a few conspicuous patterns. 4 groups of algae/detritus feeders, represented by an ascidian (h1i), a chiton (h1ii), a barnacle (h1iii) and a slipper limpet (h1iv), and 2 groups of predators/scavengers, represented by a sea anemone (c3i) and an errant polychaete (c3ii), are considered as members of the epifauna of rocky substrates. They are, accordingly, all characterized as epibionts, with the exception of group h1iv, whose members can also provide substrate for epibiotic organisms through their living or dead shells. 1 group of algae/detritus feeders, represented by a hermit crab (h4iii), and 2 groups of predators/scavengers, represented by errant polychaetes (c1i, c2ii), prefer gravelly substrates and do not play a prominent role in either epibiosis or sediment engineering. Finally, the majority of functional groups, 9 of them being algae/detritus feeders and 2 predators/scavengers, prefer muddy or sandy substrates and can be found in the sediment or at the water/sediment interface. The values assigned to them for the qualitative traits show a wide variety of combinations and they 
Table 2. Representative species and biological trait values assigned to functional groups of species. For details about the biological traits, see Table 1. Group names denote the hierarchical classification of species in, successively, consumers of algae/detritus (h) or predators/scavengers (c), 7 intermediate groups (numerals) and 20 final groups (roman numerals)

\begin{tabular}{|c|c|c|c|c|c|c|c|c|c|c|c|c|c|c|c|}
\hline Groups & Representative species & T1. temperature & T2. development & T3. dispersal & T4. fecundity & T5. tide/salinity & T6. substrate & T7. size $(\mathrm{cm})$ & T8. area & T9. position & T10. mobility & T11. growth rate & T12. lifespan (yr) & T13. epibiosis & T14. engineering \\
\hline h1i & Morchellium argus & eurythermal & brooded & short & low & stenohaline & rock & 3.3 & 0.1 & epifauna & sessile & 2.6 & 1.7 & epibiont & neutral \\
\hline h1ii & Lepidochitona cinerea & stenothermal & planktonic & short & high & stenohaline & rock & 10.8 & 4.1 & epifauna & mobile & 0.9 & 11.6 & epibiont & neutral \\
\hline h1iii & Balanus crenatus & eurythermal & planktonic & long & high & euryhaline & rock & 2.0 & 0.8 & epifauna & sessile & 2.5 & 2.0 & epibiont & neutral \\
\hline hliv & Crepidula fornicata & stenothermal & planktonic & & high & stenohaline & rock & 7.6 & 0.0 & epifauna & sessile & 1.9 & 11.2 & basibiont & neutral \\
\hline h2i & Oligochaeta & stenothermal & laid & short & low & emersed & muddy sand & 4.5 & 5.0 & infauna & mobile & 3.4 & 2.0 & neutral & destabilizer \\
\hline h2ii & Thyasira flexuosa & eurythermal & planktonic & & low & stenohaline & mud & 3.6 & 0.8 & infauna & mobile & 1.0 & 10.0 & neutral & stabilizer \\
\hline h2iii & Melinna palmata & stenothermal & brooded & short & low & stenohaline & mud & 7.5 & 0.3 & interface & sessile & 2.6 & 3.6 & neutral & stabilizer \\
\hline h2iv & Notomastus latericeus & stenothermal & brooded & short & low & stenohaline & muddy sand & 6.0 & 2.9 & interface & mobile & 2.6 & 1.9 & neutral & destabilizer \\
\hline $\mathrm{h} 3 \mathrm{i}$ & Hediste diversicolor & eurythermal & laid & short & high & emersed & muddy sand & 12.8 & 0.2 & interface & mobile & 2.1 & 3.4 & neutral & destabilizer \\
\hline h3ii & Malacoceros fuliginosus & eurythermal & planktonic & long & high & euryhaline & mud & 8.5 & 1.9 & interface & mobile & 2.5 & 2.7 & neutral & destabilizer \\
\hline h4i & Galathowenia oculata & eurythermal & planktonic & long & high & euryhaline & mud & 11.1 & 0.0 & interface & sessile & 2.7 & 4.4 & neutral & stabilizer \\
\hline h4ii & Glycymeris glycymeris & stenothermal & planktonic & short & high & stenohaline & muddy gravel & 8.0 & 1.4 & infauna & mobile & 0.8 & 15.0 & neutral & stabilizer \\
\hline h4iii & Anapagurus hyndmanni & stenothermal & planktonic & long & high & stenohaline & gravel & 10.0 & 0.1 & epifauna & mobile & 0.6 & 10.0 & neutral & neutral \\
\hline h4iv & Cerastoderma edule & stenothermal & planktonic & long & high & emersed & muddy sand & 8.6 & 0.5 & interface & mobile & 0.7 & 8.9 & neutral & stabilizer \\
\hline$c 1 i$ & Sphaerosyllis bulbosa & stenothermal & brooded & short & low & stenohaline & gravel & 1.3 & 0.5 & epifauna & mobile & 4.7 & 1.9 & neutral & neutral \\
\hline c2i & Marphysa bellii & stenothermal & planktonic & short & high & stenohaline & muddy sand & 23.3 & 0.3 & interface & mobile & 1.1 & 4.7 & neutral & neutral \\
\hline c2ii & Nephtys hombergii & stenothermal & planktonic & long & high & stenohaline & gravel & 10.5 & 0.3 & interface & mobile & 2.2 & 7.3 & neutral & neutral \\
\hline c2iii & Myrianida edwardsi & stenothermal & planktonic & long & low & stenohaline & mud & 1.4 & 3.1 & interface & mobile & 5.8 & 1.9 & neutral & neutral \\
\hline$c 3 i$ & Urticina felina & eurythermal & planktonic & short & high & euryhaline & rock & 16.7 & 10.3 & epifauna & sessile & 1.1 & 14.0 & epibiont & neutral \\
\hline c3ii & Syllis cornuta & stenothermal & planktonic & long & low & stenohaline & rock & 7.4 & 5.2 & epifauna & mobile & 2.3 & 2.3 & epibiont & neutral \\
\hline
\end{tabular}


consistently feature the lowest and highest values for all quantitative traits. They are represented by oligochaetes (h2i), bivalves (h2ii, h4ii, h4iv) and sedentary (h2iii, h2iv, h3ii, h4i) or errant (h3i, c2i, c2iii) polychaetes, and most of them play a distinct engineering role, either as sediment stabilizers or sediment destabilizers.

(a)

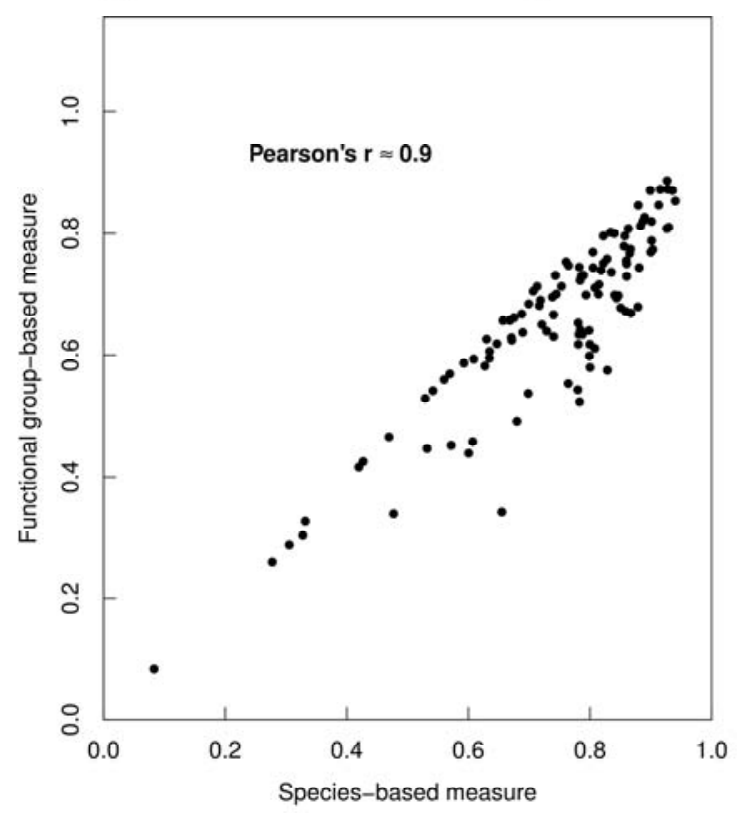

(b)

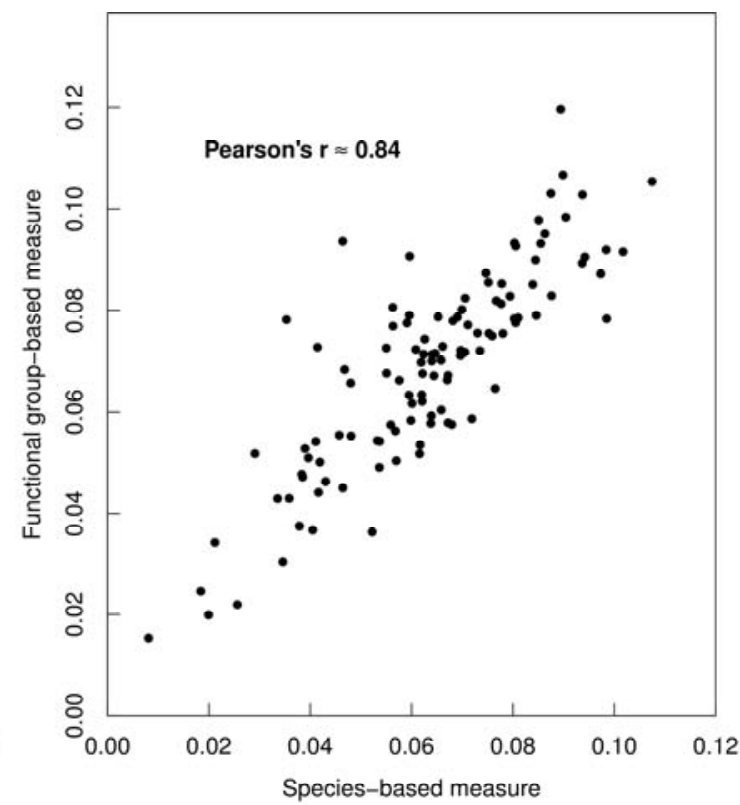

Fig. 3. Comparison of species-based and functional group-based measurements of a) taxonomic diversity and b) functional divergence for all assemblages. Both quantities were measured as Rao's quadratic entropy based on taxa abundance, by assuming functional equidistance among taxa in the former case, while employing a functional distance matrix in the latter. Pearson's correlation coefficient was calculated as a measure of the linear correlation between measurements made at the two levels of organisation

\section{2}

Evaluating biodiversity representation 
Taxonomic diversity measured at the species level correlates strongly with the same measure calculated at the level of functional groups (Fig. 3a), an indication of acceptable levels of information loss with regard to general biodiversity patterns. A few extreme deviations from the expected straight line are positioned well below it. Information on functional divergence also appears to be preserved through the transition from species to functional groups (Fig. 3b), denoting an adequate description of the system's functional components by this reduced representation. Deviations from the expected straight line are in this case positioned on both of its sides, with extreme outliers being mostly positioned above it.

Table 3. Proportion of agreement between species-based and functional groupbased calculations of community weighted mean trait values for all assemblages. For details about the biological traits, see Table 1

\section{Biological traits}

T1. low temperature tolerance

T2. early development mode

T3. larval dispersal distance

T4. maximum fecundity

T5. tidal emersion/low salinity tolerance

T6. preferred substrate type

T9. preferred substrate position

T10. adult mobility

T13. role in epibiosis

T14. role in sediment engineering

\section{Agreement proportion}

0.81

0.61

0.96

0.62

0.72

0.71

0.98

0.92

0.87

\section{3}

Assessing niche attributes preservation

The functional identity of assemblages appears in general to be conserved through the transition from species to functional groups, as community weighted 
means for most biological traits show high levels of agreement or strong correlations, when calculated at the two levels of organisation (Table $3 \&$ Fig. 4). Among all biological traits, early development mode, maximum fecundity (Table 3), and maximum size (Fig. 4a) show the lowest levels of agreement or correlation. For maximum size, the transition from one level of organisation to the other appears also to be biased, since community weighted means calculated at the species level tend to be higher than those calculated at the level of functional groups.

(a) Community weighted mean T7. size (cm)

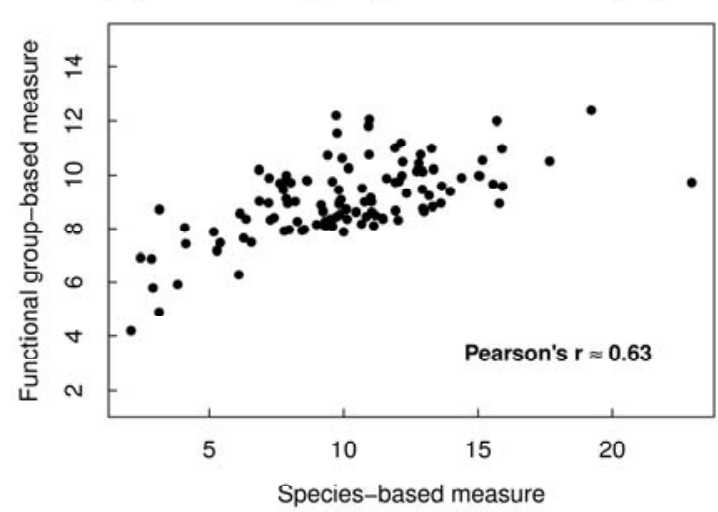

(c) Community weighted mean T11. growth rate

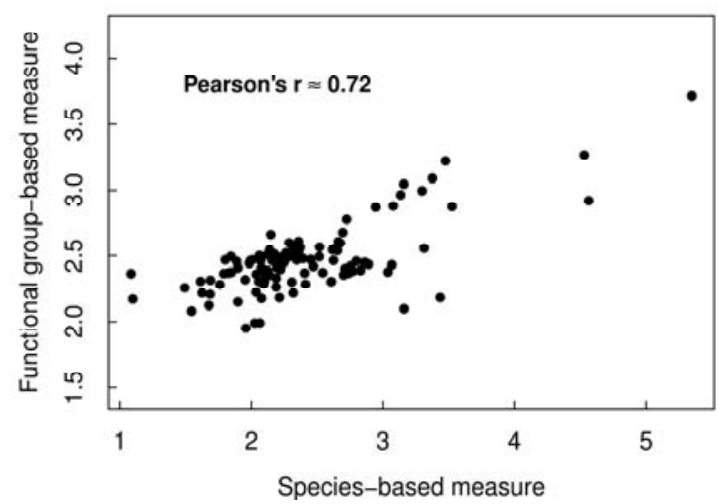

(b) Community weighted mean T8. area

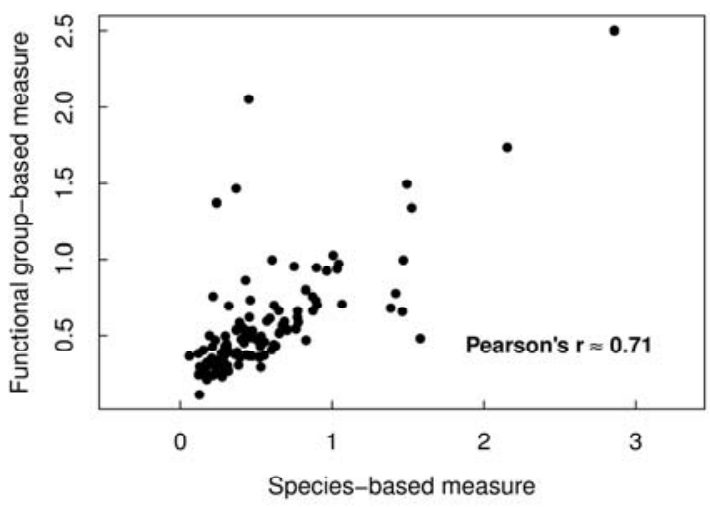

(d) Community weighted mean T12. lifespan (yr)

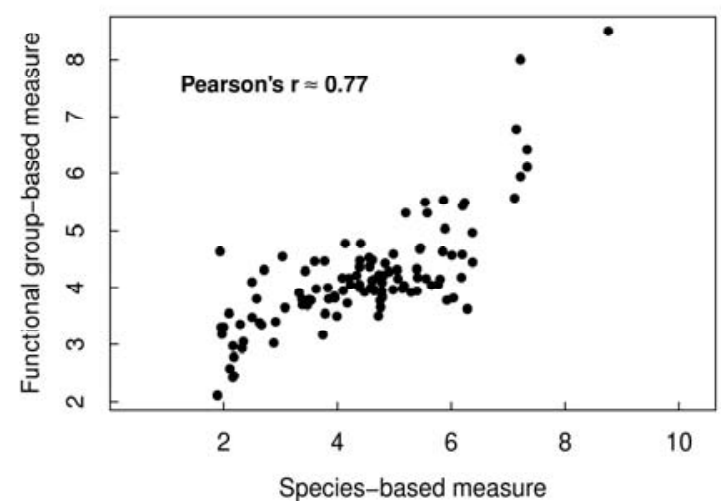

Fig. 4. Comparison of species-based and functional group-based calculations of community weighted mean trait values for all assemblages. For details about the biological traits (a-d), see Table 1. Pearson's correlation coefficient was calculated as 
a measure of the linear correlation between calculations made at the two levels of organisation

Table 4. Proportion of rejection of independence tests between the abundance of a group's species in an assemblage and the respective trait values over all functional groups and assemblages. Hoeffding's test was performed in the case of continuous biological traits (denoted by an asterisk), while Kruskal-Wallis independence test was performed in all other cases. For details about the biological traits, see Table 1

\section{Biological traits}

T1. low temperature tolerance

T2. early development mode

T3. larval dispersal distance

T4. maximum fecundity

T5. tidal emersion/low salinity tolerance

T6. preferred substrate type

T7. maximum size

T8. minimum space requirement ${ }^{\star}$

T9. preferred substrate position

T10. adult mobility

T11. population growth rate*

T12. maximum lifespan

T13. role in epibiosis

T14. role in sediment engineering

\section{Test rejection proportion}

0.02

0.11

0.02

0.08

0.08

0.05

0.08

0

0.01

0.12

0

0.05

0

0.07

\section{4}

Detecting neutral behaviour within groups

The proportion at which tests of independence between the abundance of a group's species in an assemblage and the respective trait values were rejected, is less than 0.1 for most biological traits (Table 4), supporting the assumption that trait variation within functional groups is mostly random and not associated with observed 
abundance patterns. The two traits for which this limit is exceeded (early development mode and adult mobility), show proportions of rejection of the independence tests just over the value of 0.1 . The comparison of these results with the results of the same independence tests performed at the levels of 2 feeding and 7 intermediate groups reveals a strong tendency toward a reduced proportion of rejection as the resolution of the grouping increases (see Table $S 2$ in the Supplementary Material).

4

Discussion

\section{1}

Selecting biological traits

The combination of biological trait information describing the functional role of 240 species in their communities with a conventional species abundance data set from the Rance estuary in 1995, led to the emergence of 20 groups of benthic macroinvertebrates. Like Boulangeat et al. (2012), we selected our set of traits with the goal of representing the role of organisms in the following community assembly mechanisms: resistance to perturbation, dispersal potential, environmental filtering, competitive effect, response to competition and population dynamics. We added the mechanism of biogenic habitat modification, as this is expected to be an important factor shaping benthic communities. Unlike the species abundance data set, which is spatially and temporally restricted to the system in question, the collected information on the functional role of species is highly general and could be readily employed for an application of the approach to a system with similar composition. The represented 
community assembly mechanisms would be probably retained during a transfer of the approach, but changes in specific biological traits could be well anticipated.

The transferability of each biological trait is likely to depend on a system's similarity to the Rance estuary in 1995, regarding its abiotic and biotic environment. In lack of significant anthropogenic impacts, following a normalization period in the power plant's operation during its first five years, we considered exceptionally cold winters as a source of perturbation. Disturbances, however, tend to be case-specific and their nature, whether anthropogenic or natural, would dictate the identity of the respective traits. For some systems, oxygen could be added to the list of limiting resources (Ferguson et al. 2013), which currently consists of only food and space. Different resources, such as irradiance or nutrients, would have to be considered as limiting for the members of algae-dominated systems (Alexandridis et al. 2012). A new set of resources would require a re-evaluation of the traits that represent the mechanisms of competitive effect and response to competition. Traits that describe allelopathic (Woodin et al. 1993) or symbiotic relationships (Reiss et al. 2003) should also be included, if these are mechanisms with an important role in the system.

We expect the selected mechanisms to largely control processes of community assembly but we cannot be certain that the role of each species is defined in its entirety by the selected biological traits. The use of two traits for the description of the species' role in each mechanism is expected to mitigate the effect of this uncertainty. The lack of cross-validation that it entails, precludes a full examination of the methodology's robustness, which could, however, be explored through various resampling techniques. The process of testing the main assumptions of the EGH provides the ultimate validation of the ecological relevance of each biological trait. The replacement or more realistic depiction of the biological traits for which the 
aggregation of the system results in departures from theoretical assumptions will eventually lead to the most accurate representation of the selected mechanisms. This process is for now limited to the Rance estuary as it was observed in 1995 and it will have to be repeated for the ecological aggregation of any different system. After the approach has been applied to a sufficient number of systems and once persistent patterns in the traits of the emergent groups have been investigated, we will be able to define more general biological traits and groups of benthic macroinvertebrates.

We used 14 biological traits for our functional grouping: 4 binary, 6 nominal, 2 ordinal and 2 continuous. We applied the classification procedure separately for the two feeding groups, similar to the separation of plants into 3 life form groups that Boulangeat et al. (2012) imposed, before building their own functional groups. The resolution of our traits is indicative of the uncertainty encountered during the collection of information, with binary traits showing the highest level of uncertainty and ordinal the lowest. Continuous traits are an exception, because almost all of the species biomass data from which they were derived were calculated from lengthweight relationships of questionable generality (Robinson et al. 2010). Trait information of better quality would increase their resolution and the grouping's accuracy, keep us from resorting to higher taxonomic levels to attribute trait values to species and allow us to use species biomass instead of their abundance for the assignment of trait values to the groups. The latter was dismissed at this point, because the abundance data set was considered much more reliable. Its detriment is expected to be largely alleviated by the reduced within-group biomass variation. In what would be a major improvement to the approach, information uncertainty could be addressed through the use of fuzzy coding (Chevenet et al. 1994), which can also account for spatial and temporal intra-specific trait variability (Cardeccia et al. 2016). 


\section{2}

Building functional groups

The $\mathrm{EGH}$ is based on the assumption of random dynamics within each group (Hérault 2007). The resulting ecological aggregation reduces the system by specifically subtracting an important component of what is most of the times uniformly considered as stochastic. The assignment of trait values to the emergent groups allows a functional representation of the system and an examination of the role of trait-based interactions in the regulation of system dynamics. Trophic interactions are central to the emergence of these dynamics and, besides the distinction between algae/detritus feeders and predators/scavengers, we expect the relative size of organisms to play an important role in their definition (Brose et al. 2006). The position of organisms and the mobility of their adults should dictate the partitioning of resources through a different use of space (Herman et al. 1999). Well-established ecological theory can help us define competitive interactions among functional groups, based on trade-offs in the consumption of multiple resources and in their allocation strategies (Tilman 1990). The occurrence of exceptionally cold winters would lead to distinct response patterns, based on the low temperature tolerance of each group (Beukema et al. 2000). The representative species that were assigned to the emergent groups could play a complementary role, by allowing modifications of these interactions on the basis of expert knowledge that is often hard to express in terms of biological traits and ecological theories.

A simple review of the trait values of the emergent functional groups indicates a clear distinction among benthic macroinvertebrate organisms. On the one hand, groups that prefer rocky substrates along with those that prefer gravelly ones can be 
considered as representative of organisms that belong to the epifauna and depend on the existence of hard structure on the sediment surface. Since hard structure of abiotic origin is very restricted in the Rance estuary, the occurrence of these groups should, to a large extent, be linked to basibiotic organisms, whose living or dead shells provide them with their preferred substrate. On the other hand, groups that prefer muddy or sandy substrates represent organisms that are buried deep in the sediment or at the water/sediment interface. The larger number of algae/detritus feeding groups that can be found in this category compared to the previous one may be associated with the higher occurrence of their preferred habitat near and within the Rance estuary. Epifaunal organisms are contrarily represented by more groups of predators/scavengers, possibly due to the higher structural complexity of their habitat, which in turn allows a larger diversification of predatory strategies.

\section{3}

Evaluating biodiversity representation

The loss of biodiversity information that the transition from species to functional groups entails, appears to be acceptable at both the taxonomic and functional level. In the case of taxonomic diversity, there is a clear pattern of departures from the expected straight line that are positioned below it, in agreement with the expected direction of information loss. Points that are positioned well below this line represent assemblages that consist of the most species rich groups, hence the sharp drop in taxonomic diversity when moving from species to functional groups. In the case of functional divergence, deviations can be observed on both sides of the expected straight line. This pattern is caused by the unavoidable misrepresentation of some species by their functional groups with regard to specific biological traits, which 
results in functional divergence shifting in either direction. The fact that extreme outliers are mostly positioned above this line is a direct result of the process of functional grouping. Functional divergence is an indicator of niche differentiation (Mason et al. 2005), which is expected to be maximized by a process that reduces the number of components based on their niche differences (Pavoine et al. 2005).

\section{4}

Assessing niche attributes preservation

The functional characteristics of the community, as these can be observed at the species level, appear to be preserved in the representation of the system by functional groups. The clear tendency of community weighted mean values of maximum size to be lower at the level of functional groups than at the level of species is due to the strong negative association of this trait with species abundance and the utilization of the latter for the assignment of trait values to the groups. The low levels of agreement between community weighted mean values of early development mode and maximum fecundity calculated at the level of species and functional groups show that these two biological traits are the ones for which species are the most misrepresented by their assigned groups. The fact that both traits address aspects of reproductive strategy could be a reflection of our low level of understanding with regard to the reproduction of most benthic macroinvertebrates (Tyler et al. 2012). Since these traits belong to two different community assembly mechanisms, they should be considered along with their partner traits for the representation of resistance to perturbation and dispersal potential, respectively.

\section{5}


Detecting neutral behaviour within groups

In addition to the tests originally performed by Boulangeat et al. (2012), we also investigated the second main assumption of the $E G H$, concerning the neutral behaviour of species within each group. This was done by following one of the three approaches recommended by Hérault (2007) for the validation of his hypothesis. The fact that within group abundance patterns tend to become independent of trait variation as the resolution of the grouping increases, is consistent with the assumption for a transition from trait-controlled to neutral abundance variation during the emergence of the groups. Early development mode is again one of the biological traits for which theoretical assumptions are the least supported by the results, calling for a better description of reproductive strategies. Species are also occasionally misrepresented by their functional groups with regard to the trait of adult mobility. These deviations are still only observed at an acceptably low rate. More frequent deviations could be addressed by the application of weighting during the classification procedure, aimed at increasing the contribution of the biological traits for which the grouping appears to be the most problematic.

\section{5}

Conclusions

The main contribution of the EGH (Hérault 2007) and the framework developed by Boulangeat et al. (2012) to the study of functional redundancy and the aggregation of biological communities lies in the mechanistic nature of their approach. Although statistical tools are indispensable to its implementation, they are used in support of decisions made on purely mechanistic grounds. Most notably, the acceptable level of ecological aggregation, which is a direct reflection of functional 
redundancy, is defined as the minimum number of groups for which the assumptions of the EGH are supported by observations. The crucial process of selecting biological traits is constrained by the requirement to produce the best possible representation of a list of general community assembly mechanisms. It therefore addresses the persisting issue of subjectivity in the assessment of functional redundancy (Jax 2005). The empirical testing of the grouping against theoretical assumptions, which lies at the heart of the approach, provides a framework for the critical synthesis of mechanisms that ecological theory considers as the drivers of community dynamics.

The approach focuses on the assembly of biological communities, as the driver of benthic biodiversity. This is, however, only one of the ways in which ecosystem properties are influenced by benthic organisms. Processes associated with energy and elemental cycling, habitat/refugia provision and modification of physical properties are among the most widely recognised aspects of ecosystem functioning (Frid et al. 2008). Although the approach was not designed to address these issues, links with them can be drawn at any stage, either during the construction of functional groups or during the development and analysis of models. Most of the traits that we assumed to directly represent community assembly mechanisms (with the exception of resistance to perturbation and environmental filtering) are commonly used in biological traits analyses as indirect indicators of the previously mentioned ecosystem functions (Bremner et al. 2006a). Observed trait associations and ecological theory could facilitate the collection of information that this approach lacks.

The consideration of our list of general community assembly mechanisms in conjunction with the attributes of the functional groups allowed a mechanistic interpretation of a few broad patterns of biodiversity. Our next goal is to employ ecological theory and observed trait associations, in order to inform the definition of 
rules of interaction among functional groups or between them and the environment. Similar efforts in the terrestrial environment have led to the development of dynamic and spatially explicit trait-based models of plant (Boulangeat et al. 2014) and animal communities (Scherer et al. 2015). By reproducing the assembly mechanisms of the respective systems, these studies were able to predict biodiversity responses to projected climatic and land use change. Our first objective is to answer questions regarding the stability of the system and its potential response to perturbations. Ultimately, we hope to create modelling tools reproducing the emergence of biodiversity patterns under different scenarios of environmental change. By explicitly reproducing the mechanisms that are responsible for these patterns, we expect to shed some light on their role in shaping communities of benthic macroinvertebrates.

Acknowledgements: We thank Claire Chevalier, Stanislas F. Dubois, Antoine Carlier and Patrick Le Mao for sharing their knowledge of the system and assisting in the collection of biological traits information. We also thank Amelia Curd for providing language help. Comments from the editor and anonymous reviewers helped to substantially improve the manuscript. This work was supported by LabexMer French project (ANR-10-LABX-19-01).

\section{References}

Alexandridis N, Oschlies A, Wahl M (2012) Modeling the effects of abiotic and biotic factors on the depth distribution of Fucus vesiculosus in the Baltic Sea. Mar Ecol Prog Ser 463:59-72

Bellard C, Bertelsmeier C, Leadley P, Thuiller W, Courchamp F (2012) Impacts of climate change on the future of biodiversity. Ecol Lett 15:365-377 
Beukema JJ, Essink K, Dekker R (2000) Long-term observations on the dynamics of three species of polychaetes living on tidal flats of the Wadden Sea: the role of weather and predator-prey interactions. J Anim Ecol 69:31-44

Blanchet FG, Legendre P, Borcard D (2008) Modelling directional spatial processes in ecological data. Ecol Model 215:325-336

Bonnot-Courtois C, Lafond LR (1991) Caractérisation et comportement des vases dans l'estuaire de la Rance. Rapport EDF, EPHE, Dinard

Botta-Dukát Z (2005) Rao's quadratic entropy as a measure of functional diversity based on multiple traits. J Veg Sci 16:533-540

Boulangeat I, Georges D, Thuiller W (2014) FATE-HD: a spatially and temporally explicit integrated model for predicting vegetation structure and diversity at regional scale. Global Change Biol 20:2368-2378

Boulangeat I, Philippe P, Abdulhak S, Douzet R, Garraud L, Lavergne S, Lavorel S, van Es J, Vittoz P, Thuiller W (2012) Improving plant functional groups for dynamic models of biodiversity: at the crossroads between functional and community ecology. Global Change Biol 18:3464-3475

Bremner J (2008) Species' traits and ecological functioning in marine conservation and management. J Exp Mar Biol Ecol 366:37-47

Bremner J, Paramor OAL, Frid CLJ (2006a) Developing a methodology for incorporating ecological structure and functioning into designation of Special Areas of Conservation (SAC) in the 0-12 nautical mile zone. A report to English Nature from University of Liverpool, Liverpool

Bremner J, Rogers SI, Frid CLJ (2006b) Methods for describing ecological functioning of marine benthic assemblages using biological traits analysis (BTA). Ecol Indic 6:609-622 
Brose U, Jonsson T, Berlow EL, Warren P, Banasek-Richter C, Bersier L-F, Blanchard JL, Brey T, Carpenter SR, Blandenier M-FC, Cushing L, Dawah HA, Dell T, Edwards F, Harper-Smith S, Jacob U, Ledger ME, Martinez ND, Memmott J, Mintenbeck K, Pinnegar JK, Rall BC, Rayner TS, Reuman DC, Ruess L, Ulrich W, Williams RJ, Woodward G, Cohen JE (2006) Consumerresource body-size relationships in natural food webs. Ecology 87:2411-2417

Cardeccia A, Marchini A, Occhipinti-Ambrogi A, Galil B, Gollasch S, Minchin D, Narščius A, Olenin S, Ojaveer H (2016) Assessing biological invasions in European Seas: biological traits of the most widespread non-indigenous species. Estuar Coast Shelf S (in press)

Chevenet F, Dolédec S, Chessel D (1994) A fuzzy coding approach for the analysis of long-term ecological data. Freshwater Biol 31:295-309

Clarke KR (1993) Non-parametric multivariate analyses of changes in community structure. Aust J Ecol 18:117-143

Darr A, Gogina M, Zettler ML (2014) Functional changes in benthic communities along a salinity gradient- a western Baltic case study. J Sea Res 85:315-324

Desroy N (1998) Les peuplements benthiques de substrats meubles du bassin maritime de la Rance. Évolution de la biodiversité et effets de l'activité prédatrice de Nephtys hombergii (Annélide Polychète). PhD dissertation, Université de Rennes 1, Rennes

Dray S, Dufour AB (2007) The ade4 package: implementing the duality diagram for ecologists. J Stat Softw 22:1-20

Dray S, Legendre P, Peres-Neto PR (2006) Spatial modelling: a comprehensive framework for principal coordinate analysis of neighbour matrices (PCNM). Ecol Model 196:483-493 
Ferguson N, White CR, Marshall DJ (2013) Competition in benthic marine invertebrates: the unrecognized role of exploitative competition for oxygen. Ecology $94: 126-135$

Frid CLJ, Paramor OAL, Brockington S, Bremner J (2008) Incorporating ecological functioning into the designation and management of marine protected areas. Hydrobiologia 606:69-79

Garcia C, Chardy P, Dewarumez J-M, Dauvin J-C (2011) Assessment of benthic ecosystem functioning through trophic web modelling: the example of the eastern basin of the English Channel and the Southern Bight of the North Sea. Mar Ecol 32:72-86

Garnier E, Cortez J, Billès G, Navas M-L, Roumet C, Debussche M, Laurent G, Blanchard A, Aubry D, Bellmann A, Neill C, Toussaint J-P (2004) Plant functional markers capture ecosystem properties during secondary succession. Ecology 85:2630-2637

Gower JC (1971) A general coefficient of similarity and some of its properties. Biometrics 27:857-871

Grime JP (1998) Benefits of plant diversity to ecosystems: immediate, filter and founder effects. J Ecol 86:902-910

Grime JP (1997) Biodiversity and ecosystem function: the debate deepens. Science $277: 1260-1261$

Hairston NGJr, Hairston NGSr (1993) Cause-effect relationships in energy flow, trophic structure, and interspecific interactions. Am Nat 142:379-411

Harrell FEJr, Dupont C (2015) Hmisc: Harrell Miscellaneous. R package version $3.15-0$ 
Hérault B (2007) Reconciling niche and neutrality through the emergent group approach. Perspect Plant Ecol 9:71-78

Herman P, Middelburg J, Van de Koppel J, Heip C (1999) Ecology of estuarine macrobenthos. Adv Ecol Res 29:195-240

Hoeffding W (1948) A non-parametric test of independence. Ann Math Stat 19:546557

Hubbell SP (2005) Neutral theory in community ecology and the hypothesis of functional equivalence. Funct Ecol 19:166-172

Hutchinson GE (1957) Concluding Remarks. Cold Spring Harb Sym 22:415-427

Ings TC, Montoya JM, Bascompte J, Blüthgen N, Brown L, Dormann CF, Edwards F, Figueroa D, Jacob U, Jones JI, Lauridsen RB, Ledger ME, Lewis HM, Olesen JM, van Veen FJF, Warren PH, Woodward G (2009) Review: ecological networks - beyond food webs. J Anim Ecol 78:253-269

James FC, McCulloch CE (1990) Multivariate analysis in ecology and systematics: panacea or Pandora's box? Annu Rev Ecol Syst 21:129-166

Jax K (2005) Function and "functioning" in ecology: what does it mean? Oikos $111: 641-648$

Jetz W, Carbone C, Fulford J, Brown JH (2004) The scaling of animal space use. Science 306:266-268

Jimenez H, Dumas P, Mouillot D, Bigot L, Ferraris J (2015) Harvesting effects on functional structure and composition of tropical invertebrate assemblages. ICES J Mar Sci 73:420-428

Kéfi S, Berlow EL, Wieters EA, Navarrete SA, Petchey OL, Wood SA, Boit A, Joppa LN, Lafferty KD, Williams RJ, Martinez ND, Menge BA, Blanchette CA, lles AC, 
Brose $U$ (2012) More than a meal... integrating non-feeding interactions into food webs. Ecol Lett 15:291-300

Kirby R, Retière C (2009) Comparing environmental effects of Rance and Severn barrages. Proc Inst Civ Eng Marit Eng 162:11-26

Kruskal WH, Wallis WA (1952) Use of ranks in one-criterion variance analysis. J Am Stat Assoc 47:583-621

Lavorel S, Mclntyre S, Landsberg J, Forbes TDA (1997) Plant functional classifications: from general groups to specific groups based on response to disturbance. Trends Ecol Evol 12:474-478

Laliberté E, Legendre P, Shipley B (2014) FD: measuring functional diversity from multiple traits, and other tools for functional ecology. R package version 1.0-12

Legendre P, Gauthier O (2014) Statistical methods for temporal and space-time analysis of community composition data. Proc R Soc B 281:20132728

Maechler M, Rousseeuw P, Struyf A, Hubert M, Hornik K (2013) cluster: cluster analysis basics and extensions. R package version 1.14 .4

Mason NWH, Mouillot D, Lee WG, Wilson JB (2005) Functional richness, functional evenness and functional divergence: the primary components of functional diversity. Oikos 111:112-118

McLean EL, Lasker HR (2013) Height matters: position above the substratum influences the growth of two demosponge species. Mar Ecol 34:122-129

Menge BA (1995) Indirect effects in marine rocky intertidal interaction webs: patterns and importance. Ecol Monogr 65:21-74

Muntadas A, de Juan S, Demestre M (2016) Assessing functional redundancy in chronically trawled benthic communities. Ecol Indic 61:882-892 
Ortiz M, Wolff M (2002) Dynamical simulation of mass-balance trophic models for benthic communities of north-central Chile: assessment of resilience time under alternative management scenarios. Ecol Model 148:277-291

Pavoine S, Ollier S, Pontier D (2005) Measuring diversity from dissimilarities with Rao's quadratic entropy: are any dissimilarities suitable? Theor Popul Biol $67: 231-239$

Pearson TH (2001) Functional group ecology in soft-sediment marine benthos: the role of bioturbation. Oceanogr Mar Biol 39:233-267

Petchey OL, Gaston KJ (2006) Functional diversity: back to basics and looking forward. Ecol Lett 9:741-758

Posey MH (1987) Influence of relative mobilities on the composition of bentic communities. Mar Ecol Prog Ser 39:99-104

R Core Team (2015) R: A language and environment for statistical computing. R Foundation for Statistical Computing, Vienna

Reiss H, Knäuper S, Kröncke I (2003) Invertebrate associations with gastropod shells inhabited by Pagurus bernhardus (Paguridae) - secondary hard substrate increasing biodiversity in North Sea soft $\square$ bottom communities. Sarsia 88:404415

Retière C (1994) Tidal power and the aquatic environment of La Rance. Biol J Linn Soc 51:25-36

Robinson LA, Greenstreet SPR, Reiss H, Callaway R, Craeymeersch J, de Boois I, Degraer S, Ehrich S, Fraser HM, Goffin A, Kröncke I, Jorgenson LL, Robertson MR, Lancaster J (2010) Length-weight relationships of 216 North Sea benthic invertebrates and fish. J Mar Biol Assoc UK 90:95-104 
Rosenfeld JS (2002) Functional redundancy in ecology and conservation. Oikos $98: 156-162$

Savage VM, Gillooly JF, Brown JH, West GB, Charno EL (2004) Effects of body size and temperature on population growth. Am Nat 163:429-441

Scherer C, Jeltsch F, Grimm V, Blaum N (2016) Merging trait-based and individualbased modelling: An animal functional type approach to explore the responses of birds to climatic and land use changes in semi-arid African savannas. Ecol Model 326:75-89

Sokal RR, Michener CD (1958) A statistical method for evaluating systematic relationships. Univ Kans Sci Bull 28:1409-1438

Sutherland WJ, Freckleton RP, Godfray HCJ, Beissinger SR, Benton T, Cameron DD, Carmel Y, Coomes DA, Coulson T, Emmerson MC, Hails RS, Hays GC, Hodgson DJ, Hutchings MJ, Johnson D, Jones JPG, Keeling MJ, Kokko H, Kunin WE, Lambin X, Lewis OT, Malhi Y, Mieszkowska N, Milner-Gulland EJ, Norris K, Phillimore AB, Purves DW, Reid JM, Reuman DC, Thompson K, Travis JMJ, Turnbull LA, Wardle DA, Wiegand T (2013) Identification of 100 fundamental ecological questions. J Ecol 101:58-67

Srivastava DS, Vellend M (2005) Biodiversity-ecosystem function research: is it relevant to conservation? Annu Rev Ecol Evol S 36:267-294

ter Braak CJ, Prentice IC (2004) A theory of gradient analysis. Adv Ecol Res 34:235282

Tilman D (1990) Constraints and tradeoffs: toward a predictive theory of competition and succession. Oikos 58:3-15

Tilman D (1980) Resources: a graphical-mechanistic approach to competition and predation. Am Nat 116:362-393 
Törnroos A, Bonsdorff E (2012) Developing the multitrait concept for functional diversity: lessons from a system rich in functions but poor in species. Ecol Appl 22:2221-2236

Tyler EHM, Somerfield PJ, Berghe EV, Bremner J, Jackson E, Langmead O, Palomares MLD, Webb TJ (2012) Extensive gaps and biases in our knowledge of a well-known fauna: implications for integrating biological traits into macroecology. Global Ecol Biogeogr 21:922-934

Ulanowicz RE (2004) Quantitative methods for ecological network analysis. Comput Biol Chem 28:321-339

van der Linden P, Marchini A, Dolbeth M, Patrício J, Veríssimo H, Marques JC (2016) The performance of trait-based indices in an estuarine environment. Ecol Indic 61:378-389

Walker BH (1992) Biodiversity and Ecological Redundancy. Conserv Biol 6:18-23

Woodin S, Marinelli R, Lincoln D (1993) Allelochemical inhibition of recruitment in a sedimentary assemblage. J Chem Ecol 19:517-530

Yodzis P, Innes S (1992) Body size and consumer-resource dynamics. Am Nat 139:1151-1175 